\title{
Malignant gastric hyperplastic polyp: endoscopic features of the demarcated malignant component.
}

Gastric hyperplastic polyps are associated with a risk of neoplastic transformation reaching $10 \%$ in a previous study by our team. In this work, retrospectively including 145 gastric hyperplastic polyps, a higher risk of neoplastic changes was associated with a lesion size over $25 \mathrm{~mm}$ [1]. Nevertheless, the neoplastic component was never predicted by the endoscopic examination before the resection but discovered either on the biopsy samples or on the resected specimen.

Here we report the case of a 73-year-old woman followed in our unit for hepatocellular carcinoma developed on a noncirrhotic liver (fibrosis F2) previously treated by hepatectomy. She underwent upper gastrointestinal (Gl) endoscopy to detect portal hypertension, and two gastric polyps were diagnosed at the junction of the antrum and gastric body. Helicobacter pylori infection was confirmed. One of the two polyps, measuring less than $2 \mathrm{~cm}$ in diameter, presented hyperplastic features on one part of the polyp but also an irregular pit and vascular pattern on a flat area with a demarcation line ( $\triangleright$ Fig. 1). An advanced endoscopic diagnosis was made with dual focus and acetic acid dye revealing, as previously demonstrated in Barrett's esophagus [2], a quicker acetowhitening disappearance in the malignant component compared to the hyperplastic component ( $\vee$ Video 1 ). This lesion was resected with endoscopic submucosal dissection, and histology revealed a gastric hyperplastic polyp with intramucosal adenocarcinoma resected completely with free margins (R0). This case describes for the first time a clear endoscopic diagnosis of a malignant component within a gastric hyperplastic polyp. In view of the high risk of local recurrence [3] after endoscopic resection, reserving these resections for lesions with neoplastic transformation identified
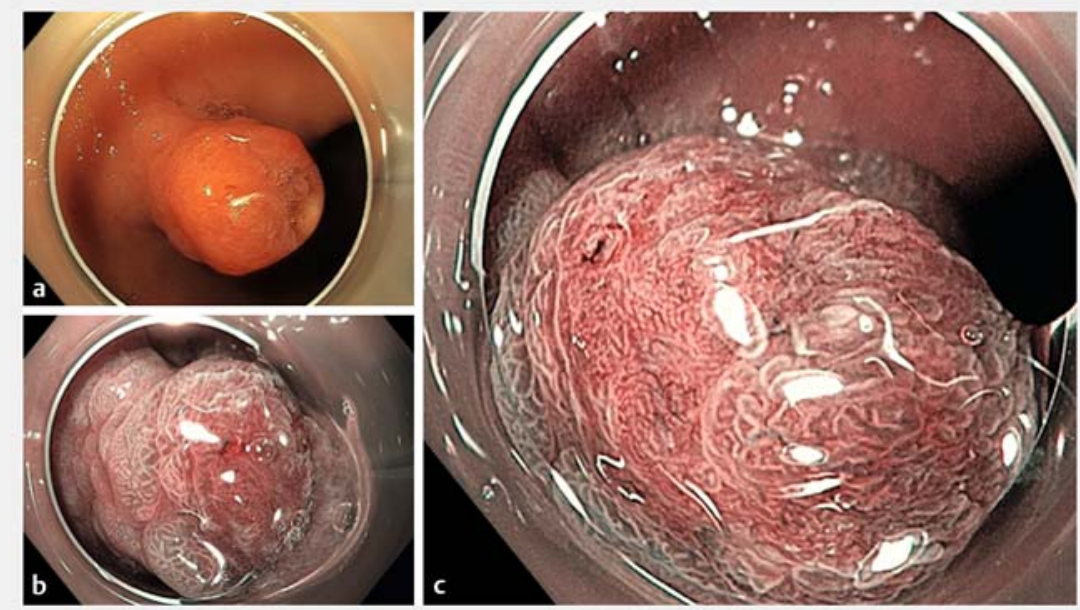

- Fig. 1 Endoscopic aspect of the malignant gastric hyperplastic polyp. a White light appearance. b Demarcation line on the edges of the malignant component. c Closed view with dual focus of the neoplastic component using narrow band imaging.

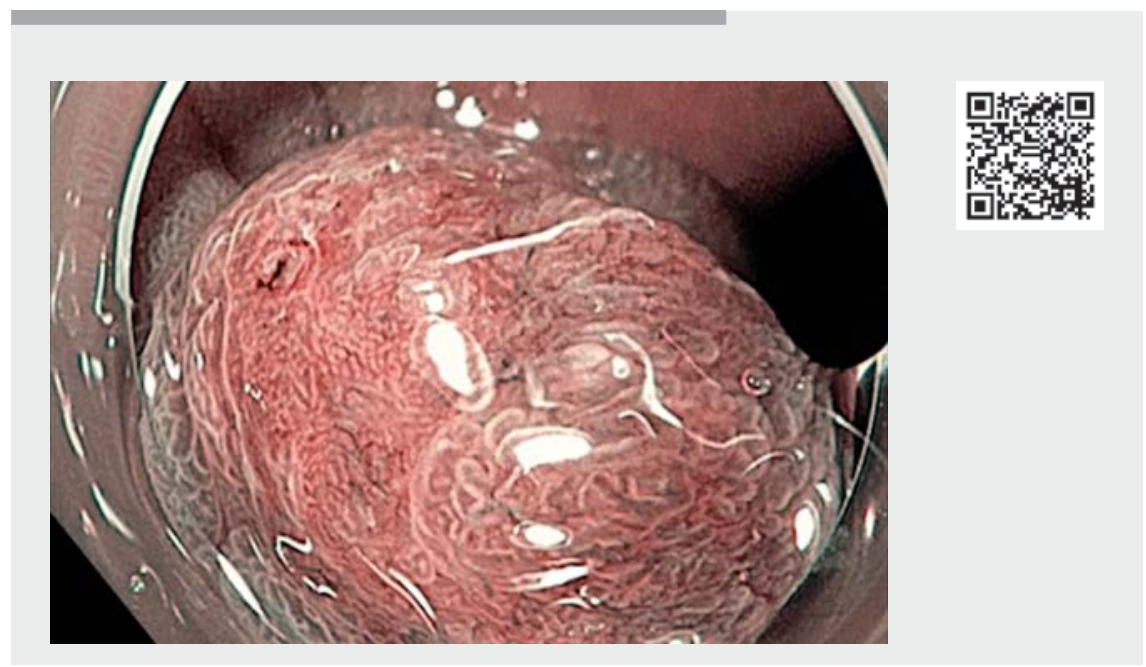

$\checkmark$ Video 1 Advanced endoscopic diagnosis for a malignant gastric hyperplastic polyp.

endoscopically could be a better option than a systematic resection of all large gastric hyperplastic polyps.

Endoscopy_UCTN_Code_CPL_1AN_2AB
Competing interests

The authors declare that they have no conflict of interest. 
Pierre Lafeuille, Christine ChambonAugoyard, Marie Napoléon, Paul Bonniaud, Thomas Lambin, Emmanuel Forté, Mathieu Pioche

Department of Endoscopy and HepatoGastroenterology, Pavillon L, Edouard Herriot Hospital, Lyon, France

\section{Corresponding author}

\section{Mathieu Pioche, MD}

Endoscopy Unit - Digestive Disease Department, Pavillon L - Edouard Herriot Hospital, 69437 Lyon Cédex, France mathieu.pioche@chu-lyon.fr
[1] Forté E, Petit B, Walter T et al. Risk of neoplastic change in large gastric hyperplastic polyps and recurrence after endoscopic resection. Endoscopy 2020; 52. doi:10.1055/ a-1117-3166

[2] Longcroft-Wheaton G, Brown ], Basford P et al. Duration of acetowhitening as a novel objective tool for diagnosing high risk neoplasia in Barrett's esophagus: a prospective cohort trial. Endoscopy 2013; 45: 426-432. doi:10.1055/s-0032-1326630

[3] Petit B, Rivory J, Lienhart I et al. Extensive hyperplastic recurrence after complete R0 resection by endoscopic submucosal dissection of a gastric hyperplastic polyp with dysplasia. Endoscopy 2015; 47: E529-E530. doi:10.1055/s-0034-1392970
Bibliography

Endoscopy 2022; 54: E26-E27

DOI 10.1055/a-1352-2200

ISSN 0013-726X

published online 19.2.2021

(c) 2021. Thieme. All rights reserved.

Georg Thieme Verlag KG, Rüdigerstraße 14, 70469 Stuttgart, Germany

\section{ENDOSCOPY E-VIDEOS}

https://eref.thieme.de/e-videos

回回 Endoscopy E-Videos is a free access online section, reporting

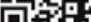
on interesting cases and new

techniques in gastroenterological endoscopy. All papers include a high quality video and all contributions are freely accessible online.

This section has its own submission website at https://mc.manuscriptcentral.com/e-videos 